\title{
Minimum Dose of Levothyroxine Restored the Autonomic Balance on a Dalmatian Female Dog with Primary Hypothyroidism
}

\author{
Paula Priscila Correia Costa' ${ }^{1}$, Stefanie Bressan Waller', Michaela Marques Rocha', \\ Danilo Galvão Rocha ${ }^{2}$, Caroline Castagnara Alves', Matheus de Azevedo Soares', \\ Eduardo Gonçalves da Silva' \& Amanda Leal de Vasconcellos ${ }^{3}$
}

\begin{abstract}
Background: Hypothyroidism is an endocrine disease that leads to a reduction in the hormones thyroxine $\left(\mathrm{T}_{3}\right)$ and triiodothyronine $\left(\mathrm{T}_{4}\right)$, which therapy with levothyroxine restores the clinical signs related to the metabolic rate. Due to the influence of thyroid hormones on the heart, which is under the constant influence of the autonomic nervous system (ANS), dogs with hypothyroidism can develop bradycardia, arrhythmia, and dysautonomia. Heart rate variability (HRV) assesses autonomic modulation by the Holter method, which is scarce in dogs. We aimed to report the cardiac and autonomic effects of the primary hypothyroidism untreated and treated with levothyroxine in a canine case by Holter monitoring.

Case: A 7-year-old female Dalmatian, weighing $36 \mathrm{~kg}$, was referred for clinical evaluation due to apathy, weight gain, low hair quality, and lethargy. On physical examination, alopecic lesions on the hind limbs and tail, as well as bradycardia with a heart rate (HR) of 40-50 beats per minute (bpm) were observed, in addition to a 3/6 mitral murmur and 2/6 tricuspid murmur. Given the suspicion of thyroid gland disorder, the blood hormonal measurement revealed an increase in thyroidstimulating hormone (TSH; $0.65 \mathrm{ng} / \mathrm{mL})$ and a decrease in free $\mathrm{T}_{4}(0.11 \mathrm{ng} / \mathrm{mL})$ and total $\mathrm{T}_{4}(0.44 \mathrm{ng} / \mathrm{mL})$, confirming primary hypothyroidism. Therapy was started with a minimum dose of levothyroxine $(0.913 \mathrm{mg}$, every $12 \mathrm{~h})$, which clinical signs were restored in 5 months of treatment, with weight loss, hair growth, and active behavior. To assess the impact of untreated and treated hypothyroidism on the patient's ANS, a Holter monitoring exam was performed for $24 \mathrm{~h}$ before and after therapy. Before treatment, the average HR was $75 \mathrm{bpm}$, and the $\mathrm{HR}<50 \mathrm{bpm}$ occurred during $05 \mathrm{~h} 20 \mathrm{~min} 36 \mathrm{~s}$. Still, 320 pause events $(>2.0 \mathrm{~s}), 1^{\text {st }}$-degree atrioventricular blocks (AVB), six ventricular ectopias events, and $2^{\text {nd }}$-degree sinoatrial block (SAB) were also observed. The ANS parasympathetic tone was significantly stimulated, highlighting bradycardia, arrhythmia, and dysautonomia. After 5 months of treatment with levothyroxine, the average HR was $89 \mathrm{bpm}$, and the HR<50 bpm occurred during $02 \mathrm{~h} 06 \mathrm{~min} 13 \mathrm{~s}$. No ventricular pauses, blocks, or ectopias were observed, showing the stimulation of sympathetic tonus, which restored HR and ANS balance. Still, it was observed that the minimum levothyroxine dose corrected cardiac changes by increasing the low frequency (LF), decreasing the high frequency (HF), and, consequently, increasing the LF/HF ratio, normalizing the frequency conditions in HRV.

Discussion: In the frequency index, HF indicates the vagal activity, whereas LF indicates both systems with parasympathetic predominance. Before treatment, the dog had a low LF/HF ratio (0.46), indicating dysautonomia with parasympathetic stimulation. After therapy, the conditions of bradycardia and functional cardiac capacity were corrected, restoring ANS, due to the serum recovery of thyroid hormones. This study reported the cardiac and autonomic effects of primary hypothyroidism untreated and treated with levothyroxine on a dog, that had intense bradycardia and abnormal stimulation of the parasympathetic tone, associated with episodes of $1^{\text {st }}$-degree AVB, ventricular ectopias, and $2^{\text {nd }}$-degree SAB. After therapy with a minimum dose of levothyroxine, there was a decrease in parasympathetic activity and an increase in sympathetic stimulus, correcting cardiac changes, and restoring the balance of ANS. As it is a simple, non-invasive, and safe tool that helps the clinician to understand cardiac autonomic modulation, it is recommended to adopt the Holter monitoring exam in cases of hypothyroidism cases to assess sympathetic-vagal balance and check potential cardiac risks.
\end{abstract}

Keywords: hypothyroidism, Holter monitoring, dysautonomia, levothyroxine, autonomic nervous system, cardiac risk.

Descritores: hipotireoidismo, monitoramento Holter, disautonomia, levotiroxina, sistema nervoso autônomo, risco cardíaco.

DOI: $10.22456 / 1679-9216.104802$

Received: 26 June 2020

Accepted: 8 November 2020

Published: 30 November 2020

${ }^{1}$ Departamento de Clínica Veterinária, Faculdade de Veterinária, Universidade Federal de Pelotas (UFPEL), Pelotas, RS, Brazil. ${ }^{2}$ Departamento de Fisiologia e Farmacologia, Faculdade de Medicina, Universidade Federal do Ceará (UFC), Fortaleza, CE, Brazil. ${ }^{3}$ Departamento de Medicina Veterinária, Universidade Estadual do Ceará (UECE), Fortaleza. CORRESPONDENCE: P.P.C. Costa [paulapriscilamv@ yahoo.com.br]. Departamento de Clínica Veterinária, Faculdade de Veterinária - UFPEL). Rua Campus Universitário s/nº. CEP 96010-900 Capão do Leão, RS, Brazil. 


\section{INTRODUCTION}

Hypothyroidism is a dysfunction in the hypothalamic-pituitary-thyroid axis that decreases the production of the hormones thyroxine $\left(\mathrm{T}_{4}\right)$ and triiodothyronine $\left(\mathrm{T}_{3}\right)$ by thyroid glands [20], being corrected by levothyroxine therapy $[10,19,20]$. This disease can be congenital [19], although rare [20], or acquired, which most canine cases are classified as acquired primary, due to lymphocytic thyroiditis or idiopathic thyroid atrophy that decrease the production of thyroid hormones $[6,20]$. Moreover, a high prevalence of circulating autoantibodies against thyroid hormones was found in Dalmatians, considered the $7^{\text {th }}$ most prevalent breed [8].

The clinical signs are related to the metabolic rate, like lethargy, weakness, weight gain, unwillingness to exercise, and cardiovascular, neuromuscular and gastrointestinal changes [20]. In the cardiac system, $10 \%$ of dogs present bradycardia and arrhythmia, with a high risk of developing dilated cardiomyopathy and atherosclerosis $[3,13,20]$ due to influence of thyroid hormones in the synthesis of cardiac proteins and the expression of cardiomyocyte structures $[3,4,9]$.

As the heart is under constant influence from the autonomic nervous system (ANS), its modulation can be assessed by heart rate variability (HRV) $[14,16,17,22]$. For this, the Holter exam for $24 \mathrm{~h}$ is the most complete method for assessing cardiac rhythm [15-17], being commonly used in hypothyroidism human [5,11,23,24], due to the risk of arrhythmias and dysautonomia. However, reports in dogs are scarce $[6,13,15]$.

We aimed to report the cardiac and autonomic effects of primary hypothyroidism untreated and treated with levothyroxine in a Dalmatian dog through Holter monitoring.

\section{CASE}

A 7-year-old female Dalmatian dog, weighing $36 \mathrm{~kg}$, was referred to a private veterinary clinic in Fortaleza, Ceará (Northeast Brazil) due to apathy, weight gain, poor hair quality, lethargy, lack of response to playing commands and facial expression described as sad a year ago (Figure 1A). On physical examination, skin lesions were observed in the hind limbs and the final region of the spine, extending to the tail, which was alopecic. The temperature was $38.2^{\circ} \mathrm{C}$, the mucous membranes were moist pink, and the capillary filling time was less than $2 \mathrm{~s}$, considered normal. On auscultation, bradycardia with heart rate (HR) between 40 to $50 \mathrm{bpm}$, apparently regular, was noted, in addition to a 3/6 mitral murmur and 2/6 tricuspid murmur.

Considering the dermatological and cardiac findings, hypothyroidism was suspected, and blood was collected to measure thyroid hormones. An increase in thyroid-stimulating hormone (TSH) levels $(0.65 \mathrm{ng} / \mathrm{mL}$; reference value - RV: $0.04-0.4 \mathrm{ng} / \mathrm{mL})$ and a decrease in free $\mathrm{T}_{4}(0.11 \mathrm{ng} / \mathrm{mL}$; RV: $0.6-2.0 \mathrm{ng} / \mathrm{mL})$ and total $\mathrm{T}_{4}(0.44 \mathrm{ng} / \mathrm{mL}$; RV: $1.2-4.0 \mathrm{ng} / \mathrm{mL})$ levels showed that the patient had primary hypothyroidism. Thus, hormonal supplementation with a minimum dose of levothyroxine (Puran $\left.\mathrm{T}^{\circledR}{ }^{\circledR}\right)^{1}[0.913 \mathrm{mg}$, every $12 \mathrm{~h}]$ was started indefinitely, in which the dog showed the remission of the clinical signs and improved the quality of life in 5 months of treatment.

To assess the impact of untreated and treated hypothyroidism on ANS, an HRV analysis was performed by Holter monitoring [24]. This method is considered the most complete to assess cardiac rhythm and the presence of abnormal complexes, verifying the autonomic condition [14,16,17,22]. Therefore, two Holter monitoring exams were performed, being one before treatment and the other after five months of levothyroxine therapy.

For this, the heart rate was monitored for $24 \mathrm{~h}$, using a portable three-channel digital device (Cardio flash plus $\left.{ }^{\circledR}\right)^{2}$ containing electrodes. After trichotomy and cleaning with $70^{\circ}$ alcohol in the thoracic region, the electrodes were fixed to the surface of the skin with adhesive tape. The electrodes were positioned in the following precordial leads: location between $5^{\text {th }}$ and $6^{\text {th }}$ intercostal spaces on the right (negative electrode) and left (positive electrode) sides; at the junction between the upper and middle $3^{\text {rd }}$ of the chest, forming the X-axis; in the manubrium region (negative electrode) and xiphoid cartilage region (positive electrode), forming the Y-axis; location between the spinous $\mathrm{T} 7$ process (negative electrode) and the opposite ventral aspect (positive electrode), forming the Z-axis. To cover and protect the electrodes, a bandage was applied to the dog's chest, as well as to the digital recording device ${ }^{2}$. The $24 \mathrm{~h}$ electrocardiographic tracings were processed using the Cardio Manager S540 software ${ }^{2}$ and always reviewed by the same veterinarian.

The parameters analyzed were the HRV electrical disturbances in the frequency domain, specifying the low frequency (LF; $0.04 \mathrm{a} 0.15 \mathrm{~Hz}$ ), and the high 
P.P.C. Costa, S.B. Waller, M.M. Rocha, et al. 2020. Minimum Dose of Levothyroxine Restored the Autonomic Balance on a

frequency $(\mathrm{HF} ; 0.150 .4 \mathrm{~Hz})$ waves components, which reflect, respectively, the sympathetic and parasympathetic ANS. Then, the LF/HF ratio was performed from the electrocardiographic record in $24 \mathrm{~h}$ of examination at each time of evaluation.

The Holter performed before treatment lasted $23 \mathrm{~h} 59 \mathrm{~m}$, and ranged from 35 to $218 \mathrm{bpm}$, with an average HR of $75 \mathrm{bpm}$. It was observed that $\mathrm{HR}<50$ bpm occurred during $05 \mathrm{~h} 20 \mathrm{~min} 36 \mathrm{~s}$, and that HR>160 bpm occurred during 00 h 06 min 56 s. Still, 320 events of pauses longer than $2.0 \mathrm{~s}$ were recorded, with the longest pause being $2.3 \mathrm{~s}$ long (Figure 1B).
Atrioventricular conduction 1:1 showed a PR interval predominantly within the normal range, ranging between 120 and $130 \mathrm{~ms}$, and interspersed with moments

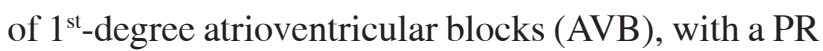
interval ranging between 140 to $160 \mathrm{~ms}$, and generally associated with HR below 85 bpm (Figure 1C). The QT intervals were within the normal range for the canine species, ranging between 230 and $250 \mathrm{~ms}$. No ST-segment depression or elevation events were recorded. There were zero supraventricular ectopic events and 6 ventricular ectopic events, in which 6 were isolated ectopias, zero paired, and zero tachycardias.
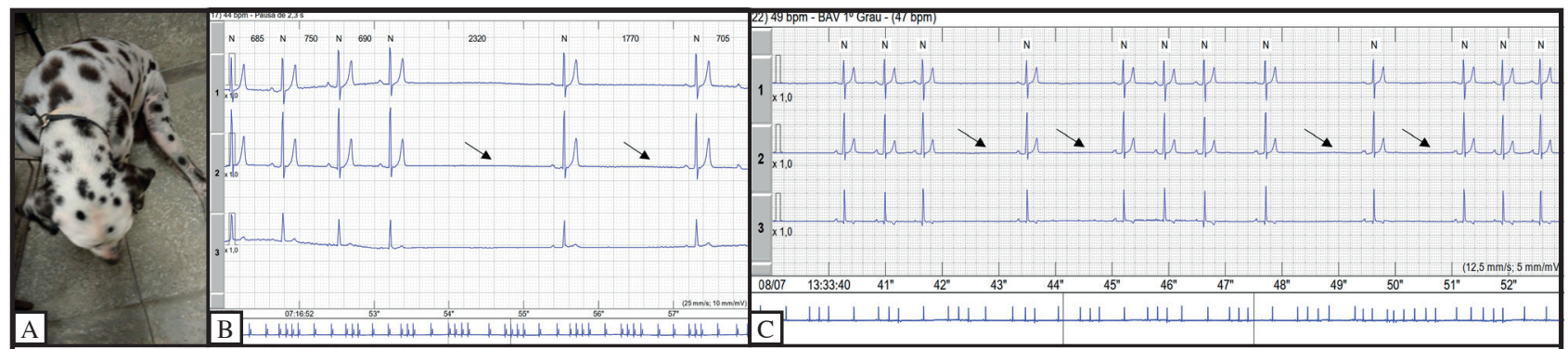

8) $59 \mathrm{bpm}$ - Arritmia sinusal - (50 bpm) - Acordada

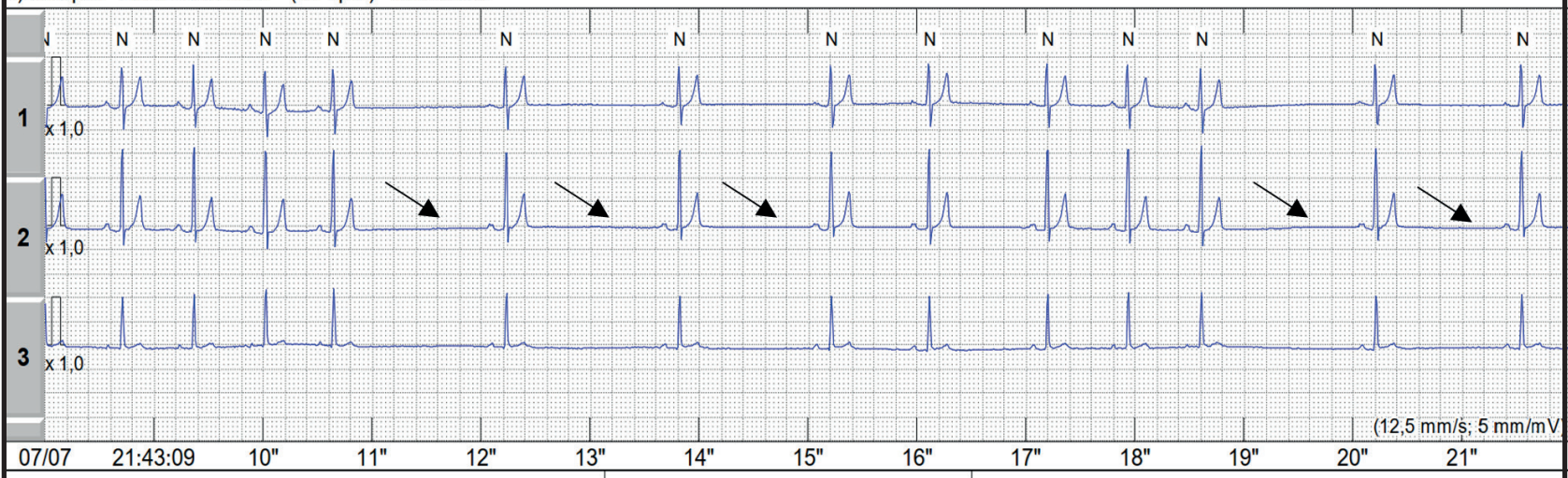

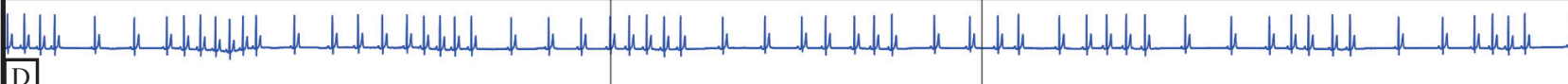

D

9) 96 bpm - Sinusal normal + BSA - (110 bpm) - Saida a rua - urinar

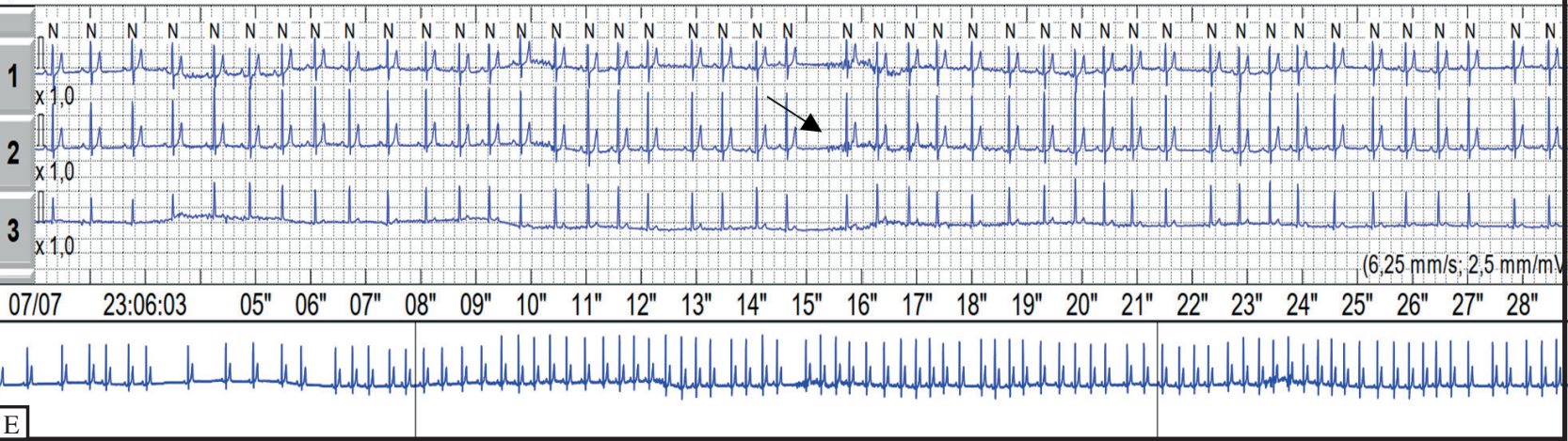

Figure 1. Primary hypothyroidism on a female Dalmatian dog with intense cardiovascular involvement, presenting fatigue after min in standing up (A) and alopecia in hind limbs. An electrocardiogram using the Holter method for $24 \mathrm{~h}$ before treatment revealed the following cardiac changes during the monitoring of beats per minutes (bpm; arrows): long pause of $2.3 \mathrm{~s} \mathrm{(B)}$, presence of $1^{\text {st }}$-degree atrioventricular block (AVB) with heart rate (HR) below $85 \mathrm{bpm}(\mathrm{C})$ and sinus arrhythmia (D). When going outside to practice urinating (E), the dog presented a sinoatrial block (SAB) between the normal sinus beats during HR of $96 \mathrm{bpm}$. These cardiac findings showed that the primary hypothyroidism significantly increased the parasympathetic tone, indicating that this endocrine disease altered the patient's autonomic nervous system. 
P.P.C. Costa, S.B. Waller, M.M. Rocha, et al. 2020. Minimum Dose of Levothyroxine Restored the Autonomic Balance on a

In this way, it was concluded that the dog presented sinus arrhythmia (Figure 1D) associated with $2^{\text {nd }}$-degree sinoatrial block $(\mathrm{SAB})$ (Figure $\left.1 \mathrm{E}\right)$ and rare moments of sinus tachycardia. Premature multifocal ventricular extrasystoles, low incidence of ventricular electrical instability, and moderate to a high incidence of atrioventricular conduction disorders have also been identified. Additionally, ventricular repolarization was noted without the risk of myocardial hypoxia. Therefore, these findings showed that the parasympathetic tone of the ANS was significantly stimulated.
In turn, the Holter test performed after five months of levothyroxine therapy lasted $23 \mathrm{~h} 24 \mathrm{~m}$, and ranged from 39 to $>200 \mathrm{bpm}$, with an average HR of $89 \mathrm{bpm}$. It was observed that $\mathrm{HR}<50 \mathrm{bpm}$ occurred during $02 \mathrm{~h} 06 \mathrm{~min} 13 \mathrm{~s}$, and that $\mathrm{HR}>120$ bpm occurred during $04 \mathrm{~h} 36 \mathrm{~min} 56 \mathrm{~s}$. There were no significant pauses or blocks (Figure 2A), and the PR intervals were within normal limits, as were the QRS complexes and ventricular repolarization. The dog did not present supraventricular ectopia, and the presence of sinus arrhythmia (Figure 2B) was considered physiological. These findings showed that there was a

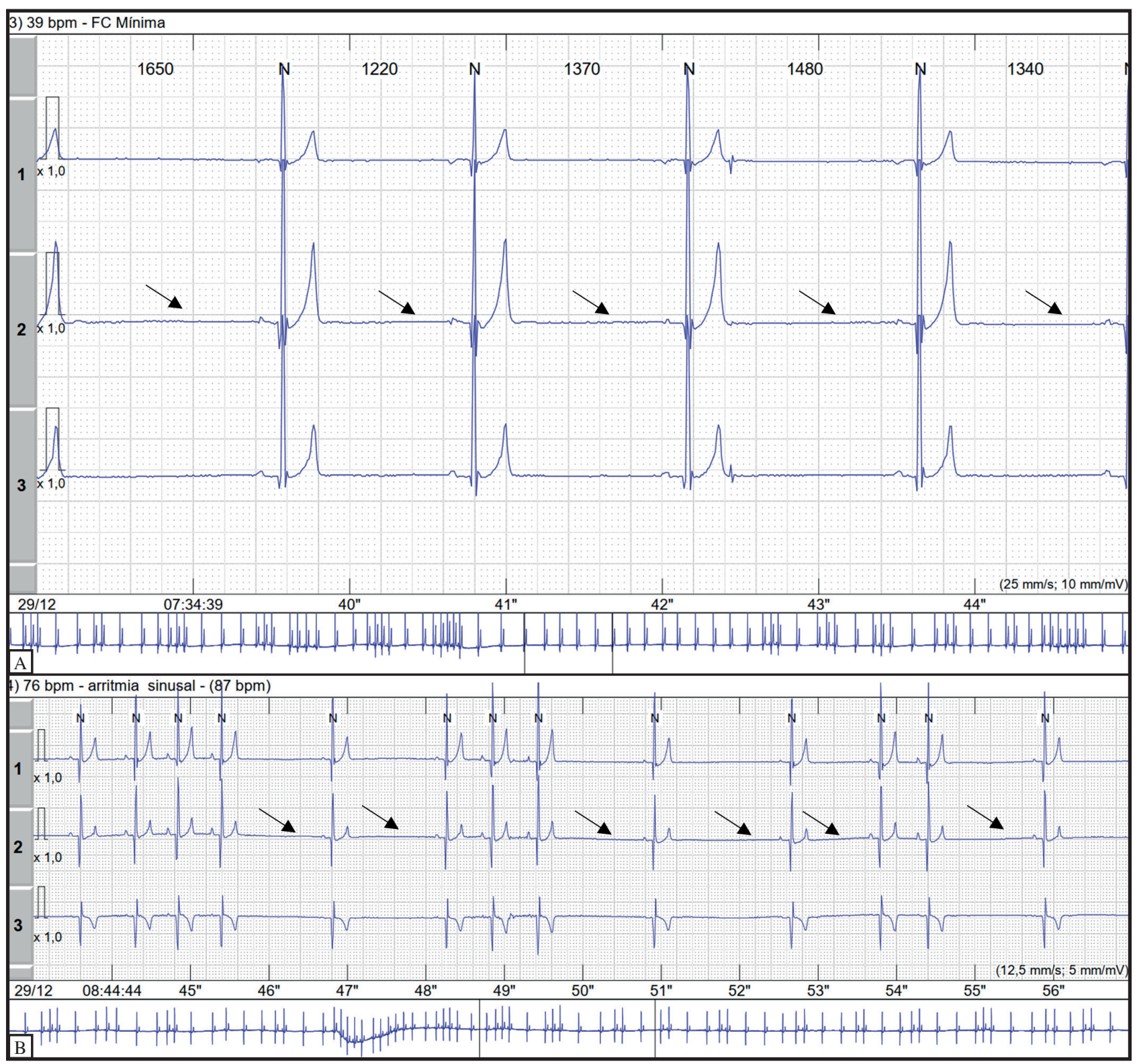

Figure 2. After 5 months of levothyroxine therapy, a new electrocardiogram by the Holter method for 24 h showed improvements in cardiac conditions. Minimum heart rate (HR) were observed with no ventricular ectopias or blocks (A), in addition to sinus arrhythmia during HR of 87 bpm (B), considered physiological. The absence of expressive stimulus of sympathetic or parasympathetic tones indicated that the hormonal therapy safely restored the balance of the autonomic nervous system. 
Table 1. Heart rate variability (HRV) frequency-domain measures before and after five months of treatment with levothyroxine in a canine case of primary hypothyroidism.

\begin{tabular}{cccc}
\hline \multirow{2}{*}{ Parameter (unit) } & \multicolumn{2}{c}{ Values found in the canine patient } & Reference values for \\
\cline { 2 - 3 } & Before treatment & After treatment & $1,182-1,565$ \\
LF power $\left(\mathrm{ms}^{2}\right)$ & 974 & 1,202 & $432-751$ \\
HF power $\left(\mathrm{ms}^{2}\right)$ & $1,887.5$ & 510 & $2.21-2.74$ \\
LF/HF ratio $(\%)$ & 0.46 & 2.36 & \\
\hline
\end{tabular}

LF: low frequency $(0.04-0.15 \mathrm{~Hz})$; HF: high frequency $(0.15-0.4 \mathrm{~Hz})$; *Values based in healthy dogs presenting body condition score number 5 [15] and in the calculation of the respective $95 \%$ confidence interval.

stimulus in the sympathetic tone, which restored HR and, therefore, the ANS balance.

In the comparative analysis of HRV in the frequency domain index (Table 1), it was observed that the hormone therapy with levothyroxine corrected cardiac changes by increasing the LF, decreasing the HF and, consequently, increasing the LF/HF ratio, normalizing the frequency conditions in the patient's HVR.

\section{DISCUSSION}

About $90 \%$ of the dogs with primary hypothyroidism present a decrease in total $\mathrm{T}_{4}$ associated with an increase in $65-75 \%$ in TSH concentration, which is considered a marker for identifying this disease [18]. In the present report, the dog had high TSH and low levels of free $\mathrm{T}_{4}$ and total $\mathrm{T}_{4}$, characterizing primary hypothyroidism [18], which is one of the most common endocrine diseases in small animals [20].

It is known that the $\mathrm{T}_{3}$ hormone plays a stimulating role in the synthesis of structural cardiac proteins, such as voltage-dependent potassium channels, $\beta 1$-adrenergic receptors, sodium/potassium ATPase, among others [4], justifying the intense impact of untreated hypothyroidism on the cardiac system [3,24]. Thus, the cardiovascular system is strongly influenced by ANS [16], since, in an episode of an imbalance between sympathetic and parasympathetic ANS, that is dysautonomia [12], it would result in cardiac changes, such as arrhythmias, sinoatrial blocks [6], dilated cardiomyopathies [3] and even risk of tissue necrosis, due to abnormalities in the myocardial microarchitecture [13]. Signs of pause, arrhythmia, and blocks were observed on the dog's electrocardiography (Figure 1B-1E), representing cardiac risks and, therefore, requiring monitoring of the cardiac condition for detailed investigation [6].
In the HRV assessment, the cardiac indexes LF and HF in the frequency domain help the veterinarians to understand the sympathetic and parasympathetic components that regulate the heart. $\mathrm{HF}$ as an indicator of vagal activity and LF is an indicator of both autonomous systems with parasympathetic predominance [14,22]. In Holter monitoring before treatment (Table 1), the dog had reduced LF associated with high $\mathrm{HF}$, which resulted in a low $\mathrm{LF} / \mathrm{HF}$ ratio. Knowing that the LF/HF ratio represents the sympathetic-vagal balance [14], these findings showed dysautonomia with a predominance of parasympathetic tonus.

Thyroid hormones stimulate sympathetic activity, especially at the cardiac level [7], as they increase the response of catecholamines on the heart, due to the positive regulation of the sarcoplasmic reticulum $\mathrm{Ca}^{2+}$-ATPase channels and $\beta$-adrenergic receptors [7]. Therefore, the dysautonomia caused by untreated hypothyroidism leads to an overlap of parasympathetic ANS in the cardiac system [3], due to the low serum concentration of $\mathrm{T}_{3}$ and $\mathrm{T}_{4}$ [6], as shown in the canine patient.

Of the cardiac autonomic dysfunctions reported in humans [5,23] and dogs [6] with hypothyroidism, the abnormal changes in HRV $[6,11,23]$ were characterized by an increase in $\mathrm{HF}$, indicating stimulating of vagal tone [23] and a decrease in LF, indicating stimulation of parasympathetic activity [14,22]. The decrease in the $\mathrm{LF} / \mathrm{HF}$ ratio before the treatment of the dog indicated a low HRV, which may have occurred due to a significant reduction in baroreflex sensitivity [21], which end up impairing the control of heart rate and vascular sympathetic tone during untreated hypothyroidism [6]. In this way, hypothyroid patients have significantly higher cardiac risks [21], and the disease control through hormone therapy is essential to maintain the patient's health $[6,10,23]$. 
The treatment is based on hormonal supplementation with sodium levothyroxine, also known as "synthetic $\mathrm{T}_{4}$ " or "l-thyroxine" [5,20]. This hormone decreases TSH secretion in the hypothalamus-pituitary-thyroid axis [25] and, thus, restores the values of $\mathrm{T}_{3}$ and $\mathrm{T}_{4}$ to normal. Started treatment, it was noted improvements in the physical condition of the dog, that lost weight, weighing $10 \mathrm{~kg}$ after 5 months of therapy, and with the growth of shiny and less brittle hair in the alopecic areas.

At the cardiac level, the second Holter monitoring exam revealed improvements in heart rate. Considering that $\mathrm{HR}<50 \mathrm{bpm}$ occurred during $05 \mathrm{~h}$ $20 \mathrm{~min} 36 \mathrm{~s}$ before treatment, it was observed that the time of occurrence of this parameter reduced to $02 \mathrm{~h}$ 06 min $13 \mathrm{~s}$ after 5 months of levothyroxine therapy, showing that the treatment corrected the bradycardia condition caused by hypothyroidism. Levothyroxine increases mean HR and P wave amplitude [10], correcting functional cardiac capacity and restoring ANS rebalancing, and the effects can already be seen in 3 months of therapy [23], due to the recovery of serum concentrations of $\mathrm{T}_{3}$ and $\mathrm{T}_{4}$ hormones.

This nervous restoration caused by levothyroxine therapy occurred due to the effect of thyroid hormones on cardiac function. It is known that the $\mathrm{T}_{3}$ hormone binds to the numerous TR $\alpha$ and TR $\beta$ receptors present in cardiomyocytes, increasing the strength of systolic contraction [9]. Although the $\mathrm{T}_{3}$ level was not measured in the dog, this hormone is mainly formed by the dissociation of $\mathrm{T}_{4}$ in peripheral tissues, such as the liver and muscles, to supply energy to local cells [18].

Thus, a measurement of $\mathrm{T}_{4}$ below the physiological level implies reduced levels of $\mathrm{T}_{3}$, which explains the behavioral changes observed before treatment, such as apathy, fatigue, and low stimulus to play commands. Mental dullness and lethargy are 2 of the most frequently documented behavioral abnormalities in hypothyroid dogs, which typically resolve within a few weeks of thyroid hormone supplementation [20]. After 5 months of levothyroxine therapy, the patient showed a significant decrease in the signs of tiredness and lethargy and became active and alert. This improvement was the result of the restoration of thyroid hormone levels, since, when reduced, decrease low metabolic rate, causing lethargy, mental confusion, and inactivity [20]. In cases of untreated hypothyroidism, the decrease of energy to local cells [18] can lead to hypometabolism, which can worsen for myocardial necrosis in severe cases [13].

Thus, in a comparative analysis of Holter monitoring exams, it was observed significant changes in the patient's cardiac condition before and after treatment with levothyroxine. During untreated hypothyroidism, the dog showed intense abnormal stimulus of the parasympathetic tone, due to a change in sinus function, in which the frequency was reduced and arrhythmic (Figure 1D). The altered conduction of the sinoatrial node can be impaired or blocked by disease or increase in vagal activity [2], which corresponded to the high values in HF (Table 1). Thus, the intranodal and sinoatrial conductions become slow, leading to bradycardia $[2,6]$, as observed before treatment because of the low values in $\mathrm{LF}$.

The episodes of $1^{\text {st }}$-degree AVB (Figure 1C) and $2^{\text {nd }}$-degree $\mathrm{SAB}$ resulted from the increase in the refractory period caused by the inhibition of L-type voltage-dependent calcium channels $[1,6]$, showing that the dog had altered atrioventricular conduction due to increased parasympathetic tone. Additionally, the 6 episodes of ventricular ectopias observed in the patient require constant cardiac monitoring, because, although rare in dogs [6], they can be predictors of death after exercise [1].

Once treatment with levothyroxine started, the dog showed a decrease in parasympathetic activity (HF) associated with an increase in the sympathetic tone stimulus, which allowed the restoration of HR without recurrence of episodes of $2^{\text {nd }}$-degree SAB and $1^{\text {st }}$-degree AVB. These findings demonstrated that the use of levothyroxine after 5 months of therapy in primary hypothyroidism corrected cardiac changes, restoring the ANS balance. There are other therapeutic options, such as the use of liothyronine sodium (synthetic triiodothyronine), which is indicated when levothyroxine therapy failed to obtain a therapeutic response [20]. However, there are no studies on the effects of the cardiovascular risks of this drug on canine hypothyroidism yet.

Considering that the Holter monitoring exam is a simple and non-invasive tool that helps the veterinarians to understand cardiac autonomic modulation $[6,14,16,17]$, it is recommended to use this exam in the clinical routine in cases of hypothyroidism for monitoring the cardiac risk and the ANS imbalance. Additionally, studies with other drugs for the treatment of hypothyroidism, such as liothyronine sodium, 
deserve to be investigated regarding the effects on the cardiac and autonomic systems, due to the lack of data.

This study reported the cardiac and autonomic effects of the untreated and treated primary hypothyroidism in a Dalmatian dog. During untreated hypothyroidism, the dog presented intense bradycardia and abnormal stimulation of the parasympathetic tone, associated with episodes of $2^{\text {nd }}$-degree $\mathrm{SAB}, 1^{\text {st- }}$ -degree AVB, and ventricular ectopias. After 5 months of a minimum dose of levothyroxine, this therapy decreased the parasympathetic activity and increased the stimulus of sympathetic tone, correcting cardiac changes, and restoring the ANS balance. Additionally, the cardiac evaluation by Holter monitoring is an auxiliary method recommended in the clinical routine for its simple and safe use during the assessment of sympathetic-vagal balance and checking of potential cardiac risks.

\section{MANUFACTURERS}

${ }^{1}$ Sanofi-Aventis Farmacêutica Ltda. São Paulo, SP, Brazil. ${ }^{2}$ Cardio Sistemas Comercial e Industrial Ltda. Paraíso, SP, Brazil.

Acknowledgements. To CAPES (Coordenação de Aperfeiçoamento de Pessoal de Nivel Superior) and to CNPq (Conselho Nacional de Desenvolvimento Científico e Tecnológico) for the fellows scholarships.

Declaration of interest. The authors report no conflicts of interest. The authors alone are responsible for the content and writing of the paper.

\section{REFERENCES}

1 Akar F.G. \& Tomaselli G.F. 2013. Electrophysiological Remodeling in Heart Failure. In: Gussak I. \& Antzelevitch C. (Eds). Electrical Diseases of the Heart - Volume 1: Basic Foundations and Primary Electrical Diseases. 2nd edn. Berlin: Springer Science \& Business Media, pp.369-386.

2 Antzelevitch C. \& Burashnikov A. 2013. Mechanisms of Cardiac Arrhythmia. In: Gussak I. \& Antzelevitch C. (Eds). Electrical Diseases of the Heart - Volume 1: Basic Foundations and Primary Electrical Diseases. 2nd edn. Berlin: Springer Science \& Business Media, pp.93-128.

3 Bilhalva M.A., Evaristo T.A., Isnardi C.P., Rocha M.M., Alves C.C., Soares M.A., Waller S.B., Borba A., Santos T.C. \& Costa P.P.C. 2020. O hipotireoidismo canino e seus efeitos sobre o sistema cardiovascular. PUBVET. 14(4): a542. DOI: 10.31533/pubvet.v14n4a542.1-6

4 Biondi B. 2012. Heart failure and thyroid dysfunction. European Journal of Endocrinology. 167(5): 609-618.

5 Celik A., Aytan P., Dursun H., Koc F., Ozbek K., Sagcan M., Kadi H., Ceyhan K., Onalan O. \& Onrat E. 2011. Heart rate variability and heart rate turbulence in hypothyroidism before and after treatment. Annals of Noninvasive Electrocardiology. 16(4): 344-350. DOI: 10.1111/j.1542-474X.2011.00461.x.

6 Costa P.P.C., Rocha D.G., Kazimoto T.A., Cabral L.A.R., Dos Santos M.H., Bezerra W.G.A., Sasahara G.L. \& Holanda T.M. 2019. Dysautonomia in a bitch with hypothyroidism. Acta Scientiae Veterinariae. 47(1): 376.

7 Danzi S. \& Klein I. 2014. Thyroid disease and the cardiovascular system. Endocrinology and Metabolism Clinics of North America. 43(2): 517-528.

8 Graham P.A., Refsal K.R. \& Nachreiner R.F. 2007. Etiopathologic findings of canine hypothyroidism. The Veterinary Clinics of North America - Small Animal Practice. 37(4): 617-631. DOI: 10.1016/j.cvsm.2007.05.002

9 Grais I.M. \& Sowers J.R. 2014. Thyroid and the heart. The American Journal of Medicine. 127(8), 691-698. DOI: 10.1016/j.amjmed.2014.03.009

10 Guglielmini C., Berlanda M., Fracassi F., Poser H., Koren S. \& Toaldo M.B. 2019. Electrocardiographic and echocardiographic evaluation in dogs with hypothyroidism before and after levothyroxine supplementation: A prospective controlled study. Journal of Veterinary Internal Medicine. 33(5): 1935-1942. DOI: 10.1111/jvim.15600

11 Gupta S., Khadka R., Thakur D., Maskey R., Mehta K.D. \& Paudel B.H. 2017. Nerve conduction and heart rate variability in patients with hypothyroidism at a Tertiary Care Centre in Eastern Nepal. Journal of the Nepal Medical Association. 56(208): 407-411.

12 Hahn C.N. 2018. Dysautonomia in Dogs. Merck Veterinary Manual. Merck Sharp \& Dohme Corp. Merck \& Co., Inc.: Kenilworth, USA. Available in: https://www.merckvetmanual.com/dog-owners/brain,-spinal-cord,-and-nervedisorders-of-dogs/dysautonomia-in-dogs. [Accessed online in June 2020].

13 Karlsberg R.P., Friscia D.A., Aronow W.S. \& Sekhon S.S. 1981. Deleterious Influence of Hypothyroidism on Evolving Myocardial Infarction in Conscious Dogs. The Journal of Clinical Investigation. 67(4): 1024-1034. DOI: 10.1172/ jci110113. 
14 Lopes P.F.F., de Oliveira M.I.B., André S.M.S., Nascimento D.L.A., Silva C.S.S., Rebouças G.M., Felipe T.R., Albuquerque Filho N.J.B. \& Medeiros H.J. 2013. Aplicabilidade Clínica da Variabilidade da Frequência Cardíaca. Revista Neurociência. 21(4): 600-603. DOI: 10.4181/RNC.2013.21.870.4p

15 Mazini A.R. 2011. Avaliação da ocorrência de arritmias e da variabilidade da frequência cardíaca em cães obesos pelo método Holter. 145f. São Paulo, SP. Dissertação (Mestrado em Ciências) - Programa de Pós-Graduação em Clínica Veterinária e Zootecnia, Universidade de São Paulo.

16 Nogueira R.B., Muzzi R.A.L., Herrera D.S., Falco I.R. \& Cavalcanti G.A.O. 2006. Avaliação do ritmo cardíaco em cães da raça Boxer saudáveis pela eletrocardiografia contínua (Holter). Arquivo Brasileiro de Medicina Veterinária e Zootecnia. 58(1): 133-136. DOI: 10.1590/S0102-09352006000100021

17 Oliveira M.S., Muzzi R.A., Araujo R.B., Muzzi L.A., Ferreira D.F., Nogueira R. \& Silva E.F. 2012. Heart rate variability parameters of myxomatous mitral valve disease in dogs with and without heart failure obtained using 24hour Holter electrocardiography. The Veterinary record. 170(24): 622. DOI: 10.1136/vr.100202

18 Panciera D.L. \& Caar A.P. 2005. Hypothyroidism. In: Panciera D.L. \& Caar A.P. (Eds). Endocrinology for the Small Animal Practitioner. 4th edn. Jackson: Teton NewMedia, pp.25-38.

19 Pisani R.B.F., Oliveira P.C., Bastos I.P.B. \& Fernandes J.I. 2017. Hipotireoidismo congênito primário em cão: relato de caso. Brazilian Journal of Veterinary Medicine. 39(4): 279-283. DOI: 10.29374/2527-2179.bjvm020817

20 Scott-Moncrieff J.C. 2015. Hypothyroidism. In: Feldman E., Nelson R., Reusch C. \& Scott-Moncrieff J.C. (Eds). Canine and Feline Endocrinology. 4th edn. Philadelphia: Saunders, pp.77-135.

21 Syamsunder A.N., Pal P., Pal G.K., Kamalanathan C.S., Parija S.C., Nanda N. \& Sirisha A. 2017. Decreased baroreflex sensitivity is linked to the atherogenic index, retrograde inflammation, and oxidative stress in subclinical hypothyroidism. Endocrine Research. 42(1): 49-58. DOI: 10.1080/07435800.2016.1181648

22 Sztajzel J. 2004. Heart rate variability: a noninvasive electrocardiographic method to measure the autonomic nervous system. Swiss Medical Weekly. 134(35-36): 514-522.

23 Xing H., Shen Y., Chen H., Wang Y. \& Shen W. 2001. Heart rate variability and its response to thyroxine replacement therapy in patients with hypothyroidism. Chinese Medical Journal. 114(9): 906-908.

24 Yildiz C., Yildiz A. \& Tekiner F. 2015. Heart rate turbulence analysis in subclinical hypothroidism heart rate turbulence in hypothyroidism. Acta Cardiologica Sinica. 31(5): 444-448. DOI: 10.6515/ACS20150428A

25 Ziglioli V., Panciera D.L., Troy G.C., Monroe W.E., Boes K.M. \& Refsal K.R. 2017. Effects of Levothyroxine Administration and Withdrawal on the Hypothalamic-Pituitary-Thyroid Axis in Euthyroid Dogs. Journal of Veterinary Internal Medicine. 31(3): 705-710. DOI: 10.1111/jvim.14711 